\title{
INFLUENCE OF INLET GEOMETRY ON THE EFFICIENCY OF 1 MW STEAM TURBINE
}

\author{
Arkadusz Koprowski \\ Dominik Gotowski \\ Institute of Fluid-Flow Machinery Polish Academy of Sciences \\ Aeroelasticity Departement \\ Fiszera Street 14, 80-952 Gdansk, Poland \\ tel.: +4858 6995169, fax: +48583416144 \\ e-mail:akoprowski@imp.gda.pl \\ Romuald Rzadkowski \\ Ryszard Szczepanik \\ Air Force Institute of Technology \\ Ksiecia Boleslawa Street 6, 01-494 Warsaw, Poland \\ tel.: +4822 6851300,fax: +48226851313 \\ e-mail: z3@imp.gda.pl,ryszard.szczepanik@itwl.pl
}

\begin{abstract}
The process of the design of the 1 MW steam turbine includes designing the stator and rotor blades, the steam turbine inlet and exit, the casing and the rotor. A turbine that operates at rotation speeds other than 3000 rpm requires a gearbox and generator with complex electronic software. This article analyses the efficiency of eight turbine variants, including seven inlet geometries and three stages of stator as well as an eight variant with one of the inlets, all three stages and an outlet.

This article analyses the efficiency of 8 turbine variants, including four spiral inlet geometries and tree stages in a $1 \mathrm{MW}$ steam turbine. In the article, inlets and 1st stator blades of various geometries were analysed to obtain maximal turbine efficiency. Changing the inlet spiral from one pipe to two pipes increased the turbine efficiency. The geometry of the blades and turbine inlets and outlet was carried out using Design Modeller. The blade mesh was prepared in Turbo Grid and inlet in ANSYS Meshing.
\end{abstract}

Keywords: turbine engine, steam turbine, turbine inlet

\section{Introduction}

The inlet of a steam turbine consists of inlet boxes for partial admission. In small turbines, the design of the inlet is simplified to lower production costs.

Kryłłowicz et al. [1] describes two small steam turbines, $50 \mathrm{~kW}$ (condensing steam turbine) and $165 \mathrm{~kW}$ (backpressure turbine), with $340^{\circ} \mathrm{C}$ inlet temperatures, 12 bar inlet pressures, $270 \mathrm{~kg} / \mathrm{h}$ mass flow and $6276 \mathrm{rpm}$. The inlet turbine was typical for a classical turbine.

This article analyses the efficiency of 8 turbine variants, including four spiral inlet geometries and tree stages in a $1 \mathrm{MW}$ steam turbine with a $30 \mathrm{t} / \mathrm{h}$ mass flow.

\section{Numerical analysis}

The steady viscous calculations of the 4 inlets and 3 stages ( 32 stators and 99 rotor blades in each stage) were carried out using ANSYS CFX. The geometry of the blades and turbine inlets and outlet was carried out using Design Modeller. The blade mesh was prepared in TurboGrid and inlet in ANSYS Meshing. 
The inlet pressure was $9 \mathrm{bar}$, temperature $493.15 \mathrm{~K}\left(220^{\circ} \mathrm{C}\right)$, the outlet pressure was $4 \mathrm{bar}$. The 8 turbine variants were analysed in terms of turbine efficiency. The steady flow through the 7 geometries and three stages as well as the eight variant of one of the inlets with three stages and an outlet were calculated to see how they affect turbine efficiency.

\section{Variant 1}

The circular pipe was connected to a rectangular channel; at a slight angle to the spiral for a smoother flow into the spiral. The spiral outlet is in the form narrowing diffuser leading the steam to the stator blades (Fig. 1). The inlet spiral causes a reversing of the flow direction in the stator. The profile of first stator is S-9012A [2] and the number of the stators is 32.

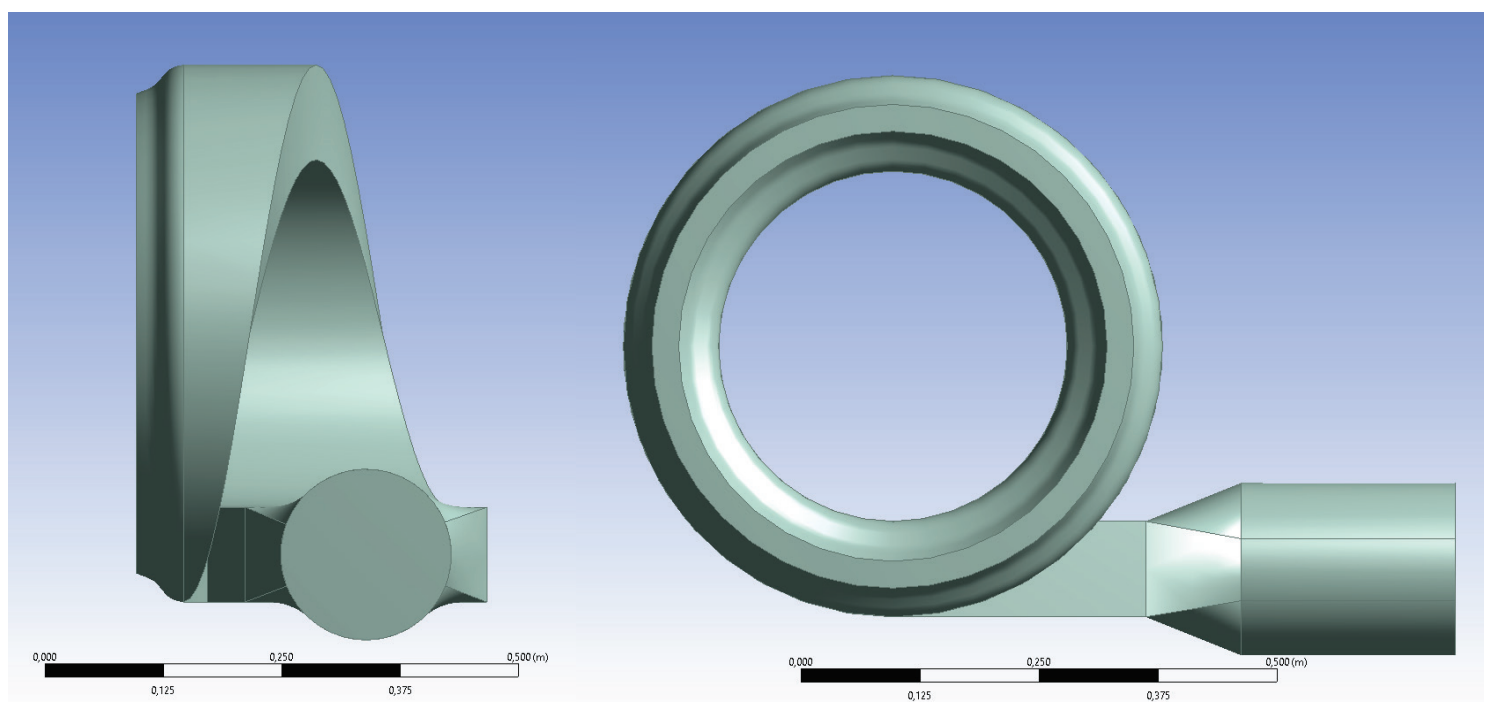

Fig. 1. Geometry of the turbine inlet, variant I

The stall flow region is visible in the inlet pipe area and spiral (Fig. 2) and in the stator blades (Fig. 3). The velocity is perpendicular to the pressure side.

The turbine power was $1.368 \mathrm{MW}$ and mass flow $9.78 \mathrm{~kg} / \mathrm{s}(35.21 \mathrm{t} / \mathrm{h})$ with $86.17 \%$ efficiency. The pressure drop in inlet was $5.64 \mathrm{kPa}$.

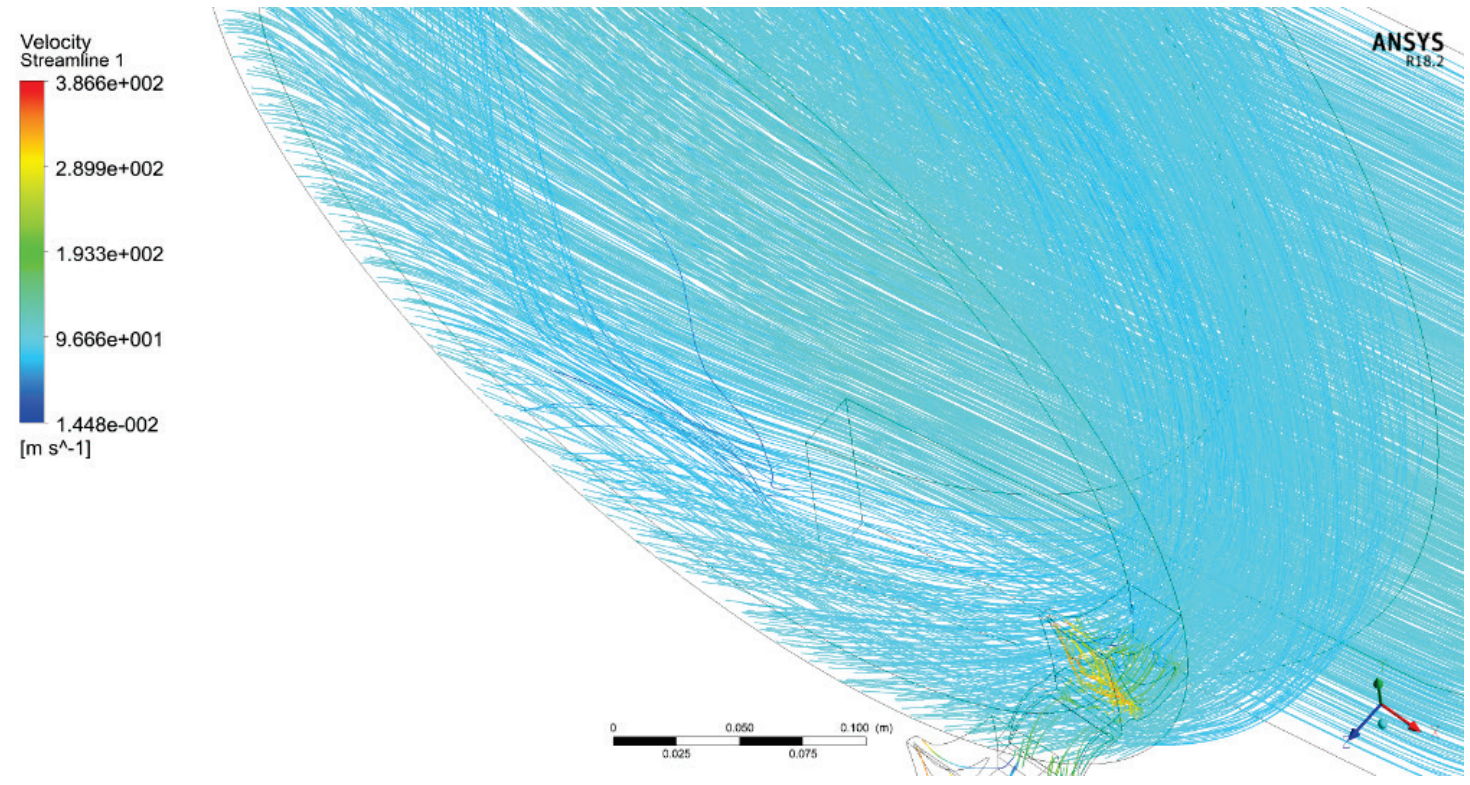

Fig. 2. Variant 1 inlet flow 

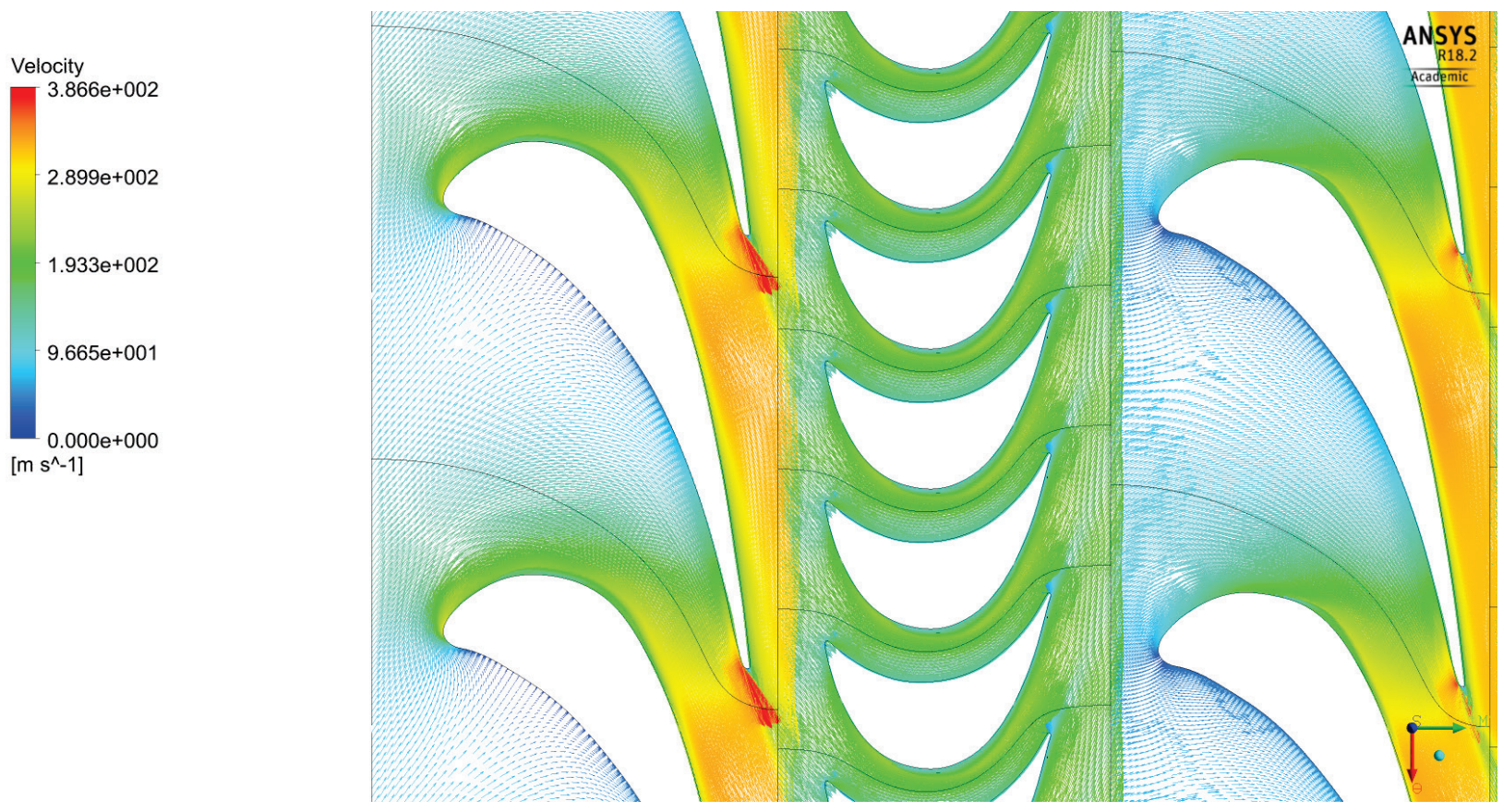

Fig. 3. The velocity field in 0.5 length stator blade, variant 1

\section{Variant 2}

Variant 2 had the same inlet spiral geometry as Variant 1, but a different 1st stator (S-5515A [2]) profile and number of stator blades was changed to 39. With the profile changed, flow in stator region did not stall and the velocity vector was not perpendicular to the pressure side (Fig. 4).
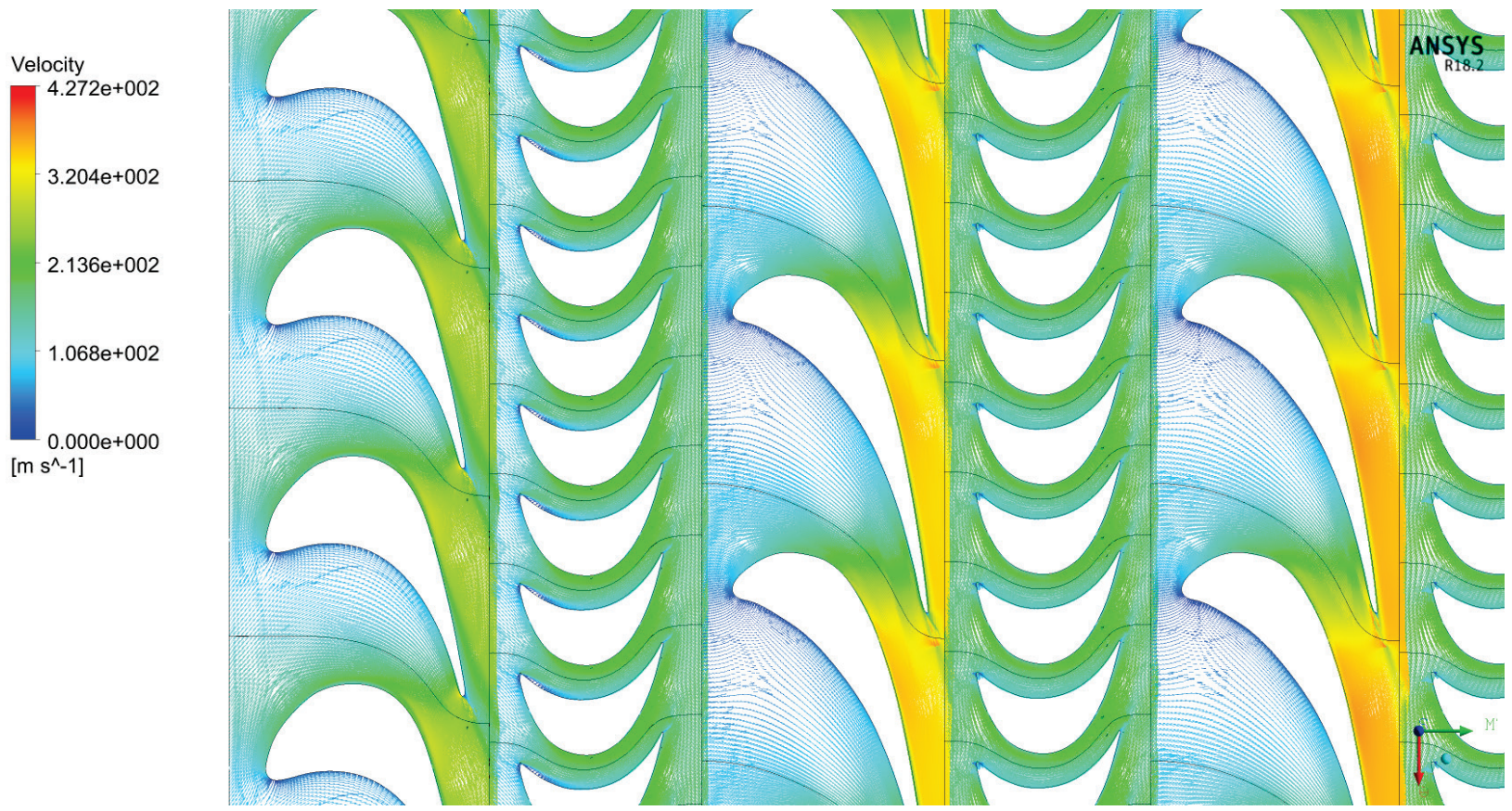

Fig. 4. Velocity field in 0.5 length stator blade, variant 2

The turbine power was $1.516 \mathrm{MW}$ and mass flow $10.73 \mathrm{~kg} / \mathrm{s}(38.64 \mathrm{t} / \mathrm{h})$. The efficiency was $86.9 \%$. The pressure drop in inlet was $6.55 \mathrm{kPa}$. Changing the 1 st stator profile in Variant 2 increased the efficiency from $86.17 \%$ to $86.9 \%$ and allowed the steam to flow in the stator without stalling. 


\section{Variant 3}

The circular pipe was connected to the rectangular channel at a zero angle to spiral. The profile of the 1st stator was S-9012A [2] and the number of stators was 32. The steam in the outlet of the spiral flowed along the inner spiral surface. In variants 1 and 2, the steam flowed in the middle of the spiral. A diffusor in this case was not applied (Fig. 5).

The flow stalled in the stator (Fig. 6) which caused efficiency to decrease to $83.7 \%$.

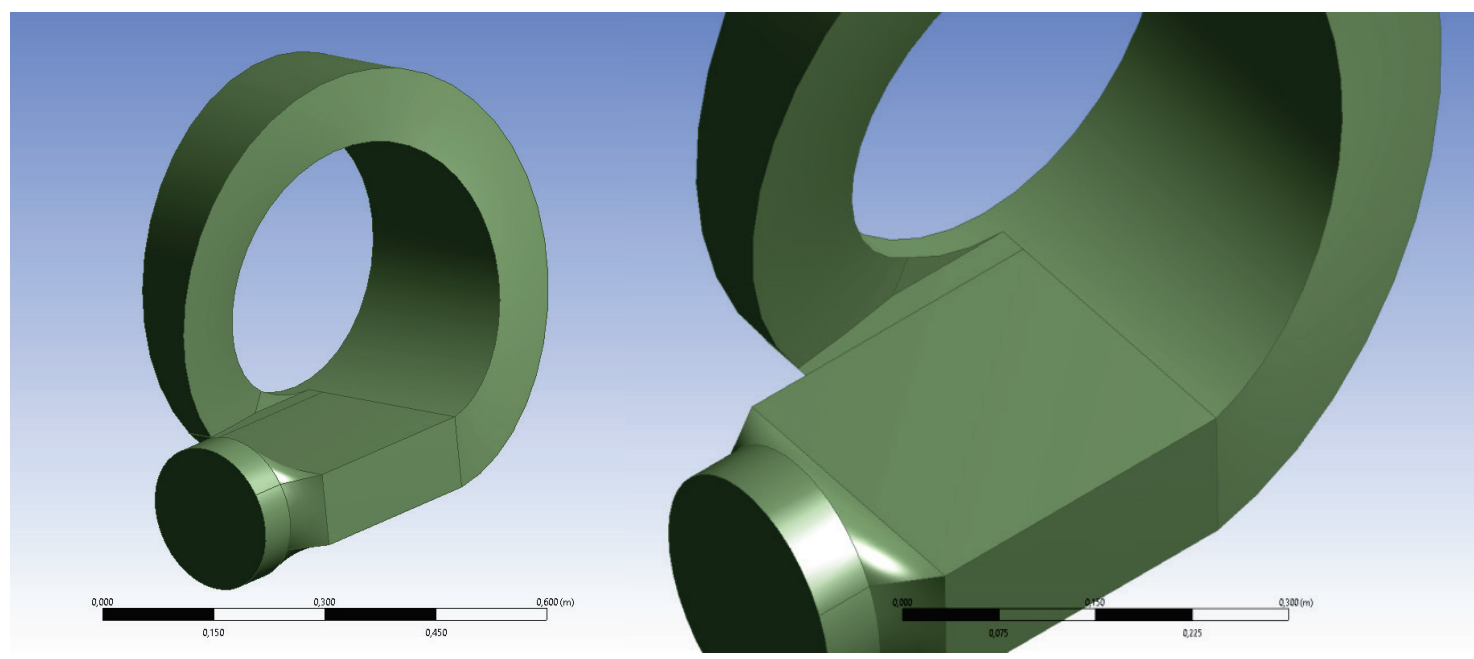

Fig. 5. The geometry of the turbine inlet, variant 3

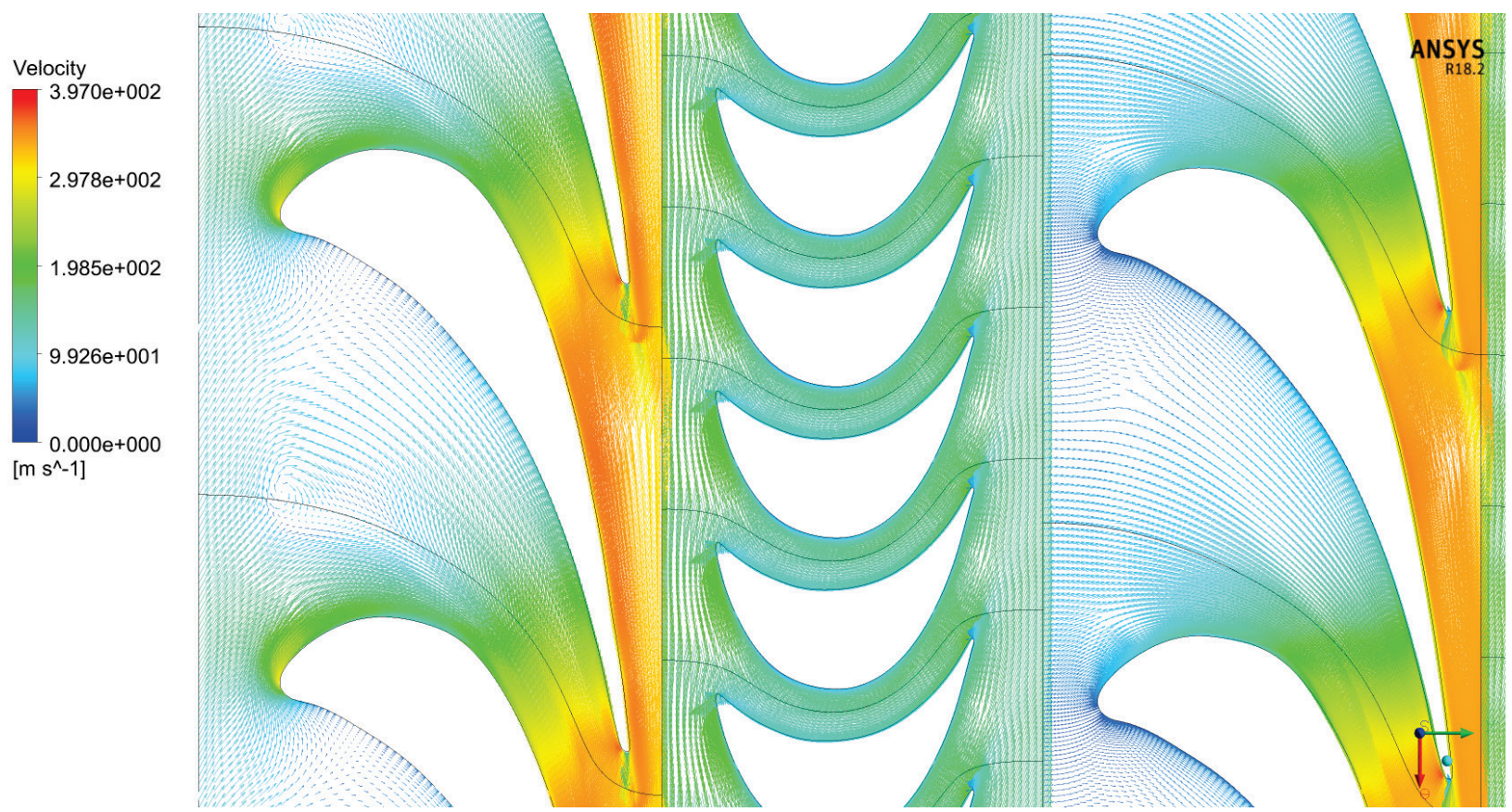

Fig. 6. The velocity field in 0.5 length stator blade, variant 3

The turbine power was $1.293 \mathrm{MW}$ and the mass flow was $9.50 \mathrm{~kg} / \mathrm{s}(34.21 \mathrm{t} / \mathrm{h})$. The pressure drop in the inlet was $21.15 \mathrm{kPa}$. Changing the angle of the inlet pipe decreased efficiency to $83.7 \%$ and caused a perpendicular flow on the pressure side as in Variant 1.

\section{Variant 4}

The geometry of Variant 4 was the same as in Variant 3 but the profile of the 1st stator (S-5515A [2]) was changed. The number of stator blades was increased to 39. 
This profile altered the flow to uninstall at 0.5 of the blade length but a stall occurred in the root area and at the blade tip.

The turbine power was $1.458 \mathrm{MW}$ and mass flow $10.49 \mathrm{~kg} / \mathrm{s}(37.75 \mathrm{t} / \mathrm{h})$. The pressure drop in inlet was $24.49 \mathrm{kPa}$. Changing the stator profile in Variant 4 increased turbine efficiency from $83.7 \%$ to $85.69 \%$.

\section{Variant 5}

The inlet spiral in Variant 5 was changed in order to stop the flow direction from reversing (Fig. 7). The profile of 1st stator (S-9012A [2]) was shorten from $62.5 \mathrm{~mm}$ to $56 \mathrm{~mm}$ and the number of stator was 32. The stator blades in other stages were the same as in variants 1 to 4 . The flow velocity is shown in Fig. 8. The flow did not stall.

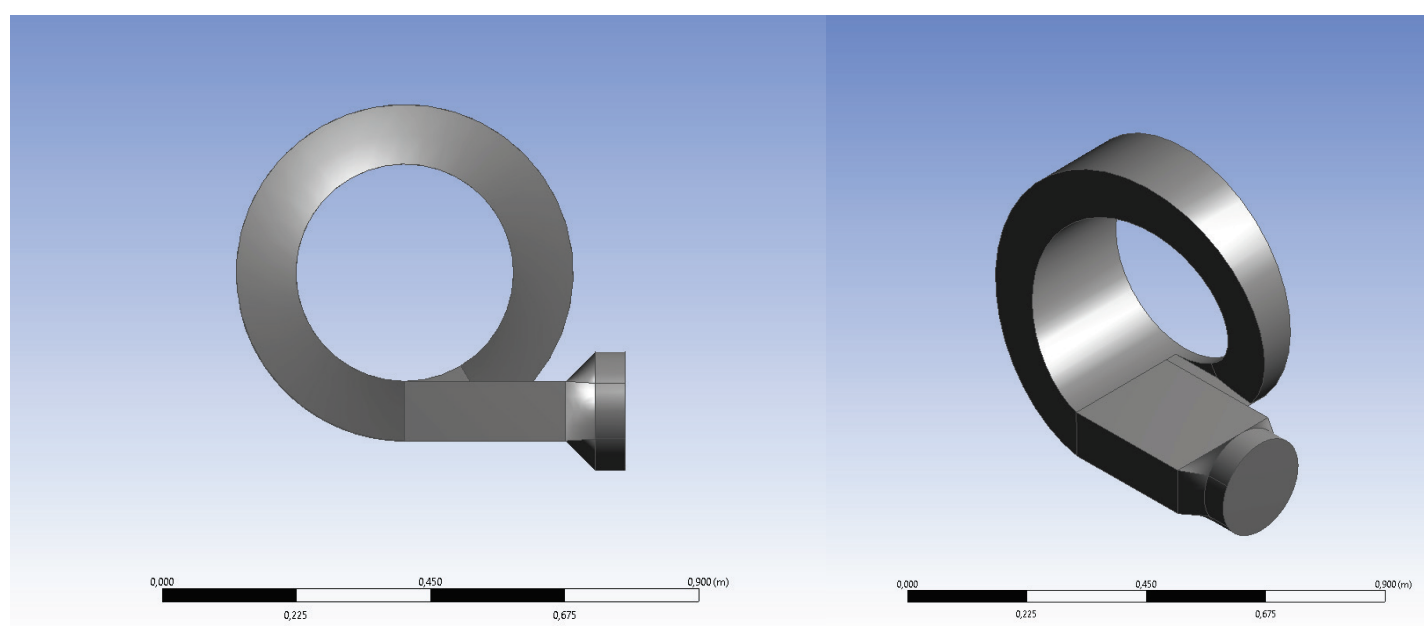

Fig. 7. Geometry of the turbine inlet, variant 5

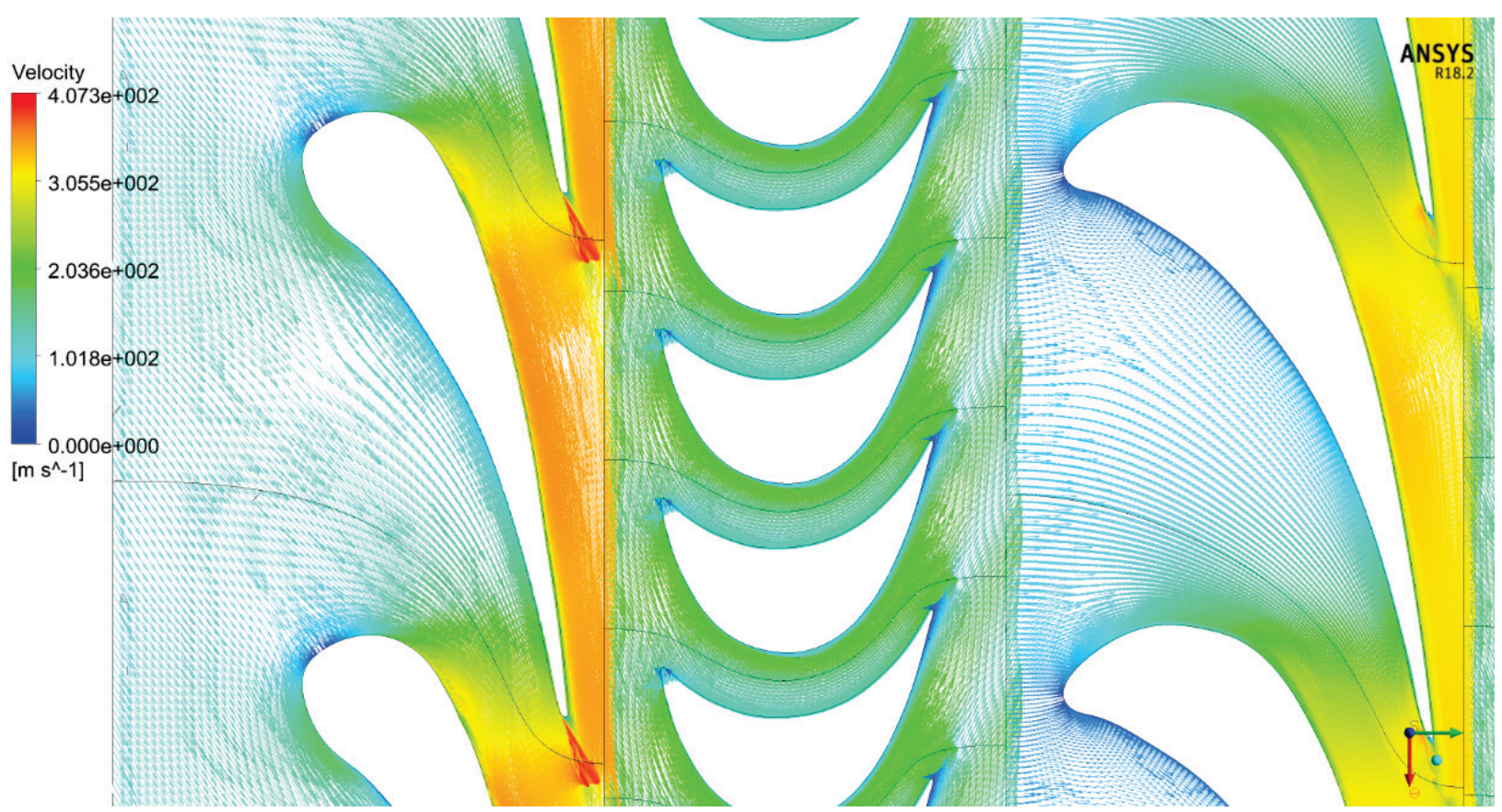

Fig. 8. Velocity field in 0.5 length stator blade, variant 5

The turbine power was $1.373 \mathrm{MW}$ and mass flow $9.68 \mathrm{~kg} / \mathrm{s}(34.86 \mathrm{t} / \mathrm{h})$. The pressure drop in inlet was $20.99 \mathrm{kPa}$. Changing the inlet in Variant 5 increased turbine efficiency from $85.7 \%$ to $87.3 \%$. 


\section{Variant 6}

In this case, the profile of the 1st stator (S-9012A [2]) was shorten from $62.5 \mathrm{~mm}$ to $54 \mathrm{~mm}$, the suction side was changed to reduce the blade thickness and number of stators was 32 .

The turbine power was $1.428 \mathrm{MW}$ and mass flow $10.08 \mathrm{~kg} / \mathrm{s}(36.31 \mathrm{t} / \mathrm{h})$. The pressure drop in inlet was $23.02 \mathrm{kPa}$. Changing the geometry of the 1st stator in Variant 6 decreased turbine efficiency from $87.3 \%$ to $87.15 \%$.

\section{Variant 7}

In this case, in contrast to Variants 1-6, two inlet pipes were used instead of one (Fig. 9).

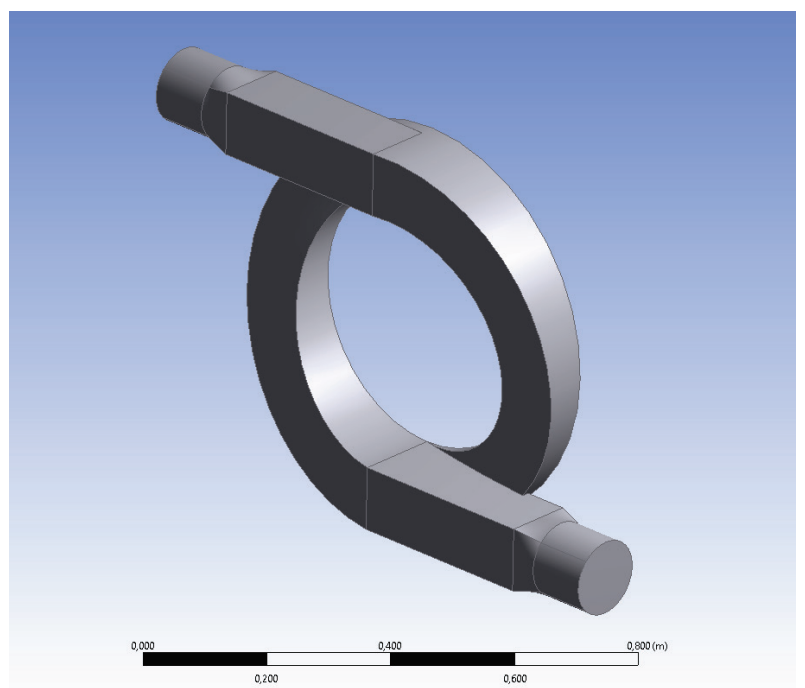

Fig. 9. Geometry of the turbine inlet, variant 7

The turbine power was $1.178 \mathrm{MW}$ and mass flow $8.21 \mathrm{~kg} / \mathrm{s}(29.31 \mathrm{t} / \mathrm{h})$. The pressure drop in inlet was $1,24 \mathrm{kPa}$. Changing the geometry of the inlet in Variant 7 increased turbine efficiency from $87.3 \%$ to $88.87 \%$.

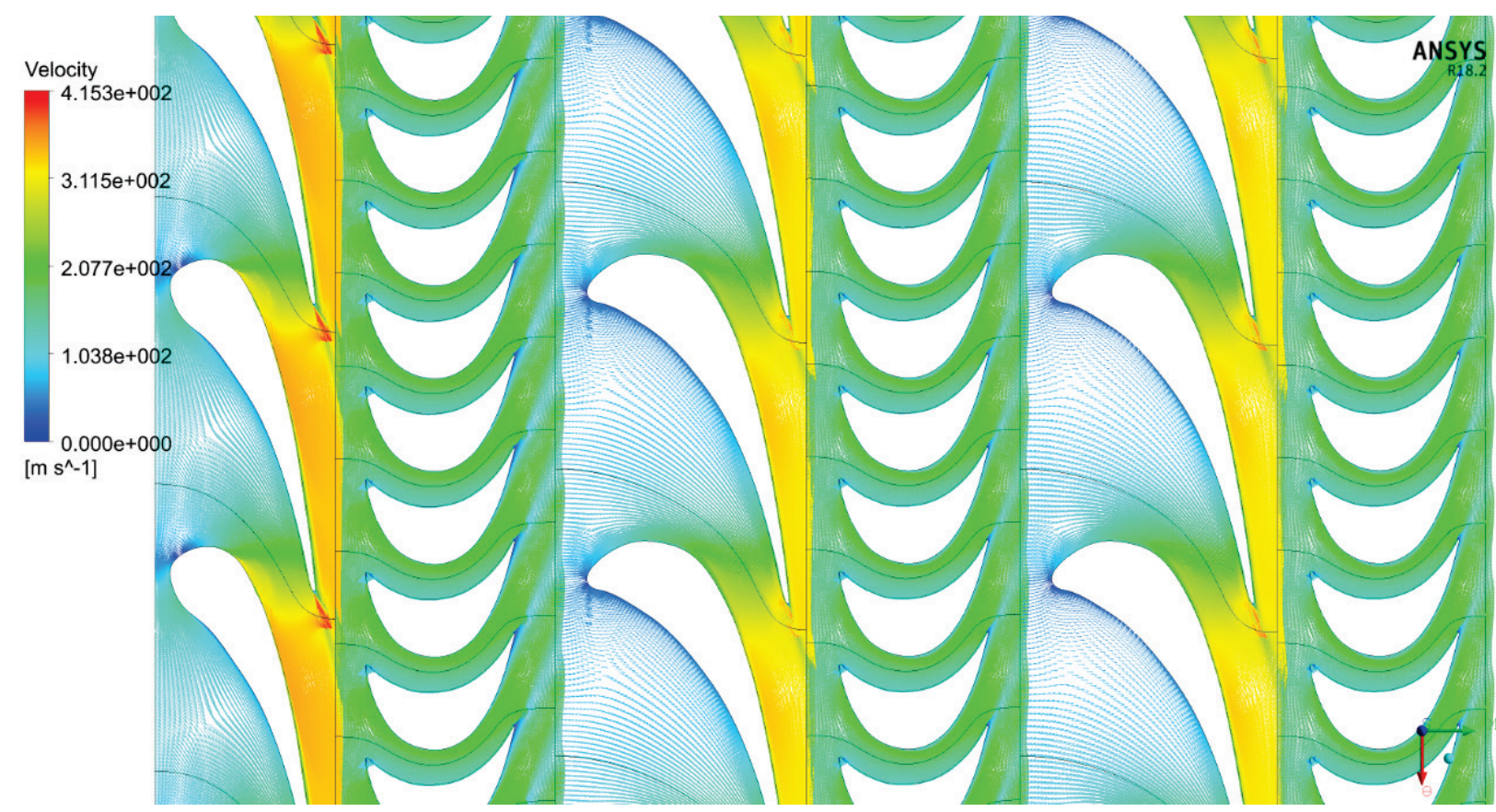

Fig. 10. Velocity field in 0.5 length stator blade, variant 7 
Variant 8

Variant 8 had the same inlet as Variant 7 and three stages, but also an outlet (Fig. 11). The profile of the 1st stator S-9012A [2].
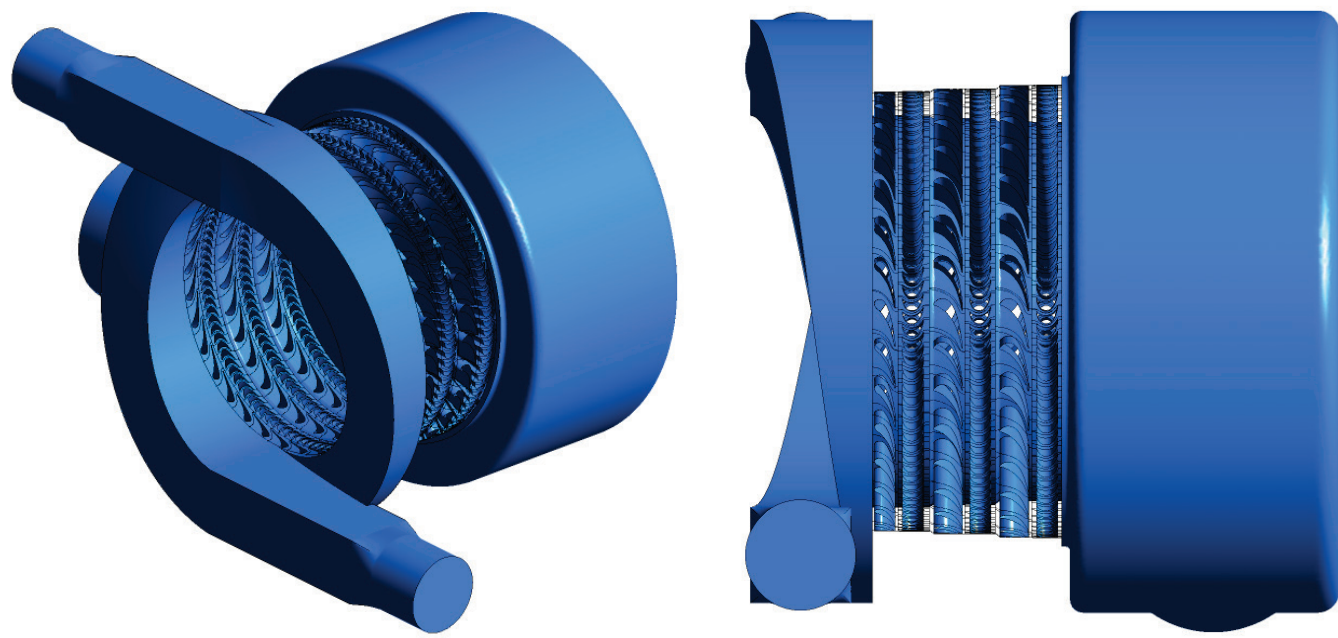

Fig. 11. Geometry of the turbine inlet, 3 stages and outlet, variant 8

The turbine power was $1.100 \mathrm{MW}$ and the mass flow $7.99 \mathrm{~kg} / \mathrm{s}(28.76 \mathrm{t} / \mathrm{h})$. The pressure drop in inlet was $1.18 \mathrm{kPa}$. Including the outlet, decreased turbine efficiency from $88.87 \%$ (Variant 7 ) to $85.31 \%$. The outlet area caused the flow to whirl in many places, which decreased turbine efficiency. The flow velocity is shown in Fig. 12. The flow did not stall.

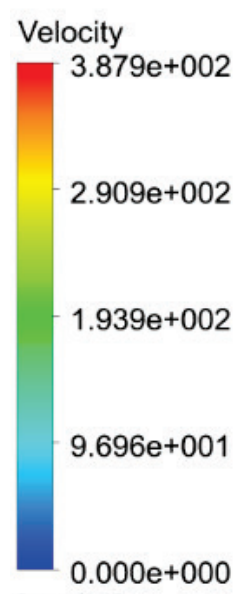

$\left[\mathrm{m} \mathrm{s} \mathrm{s}^{\wedge}-1\right]$

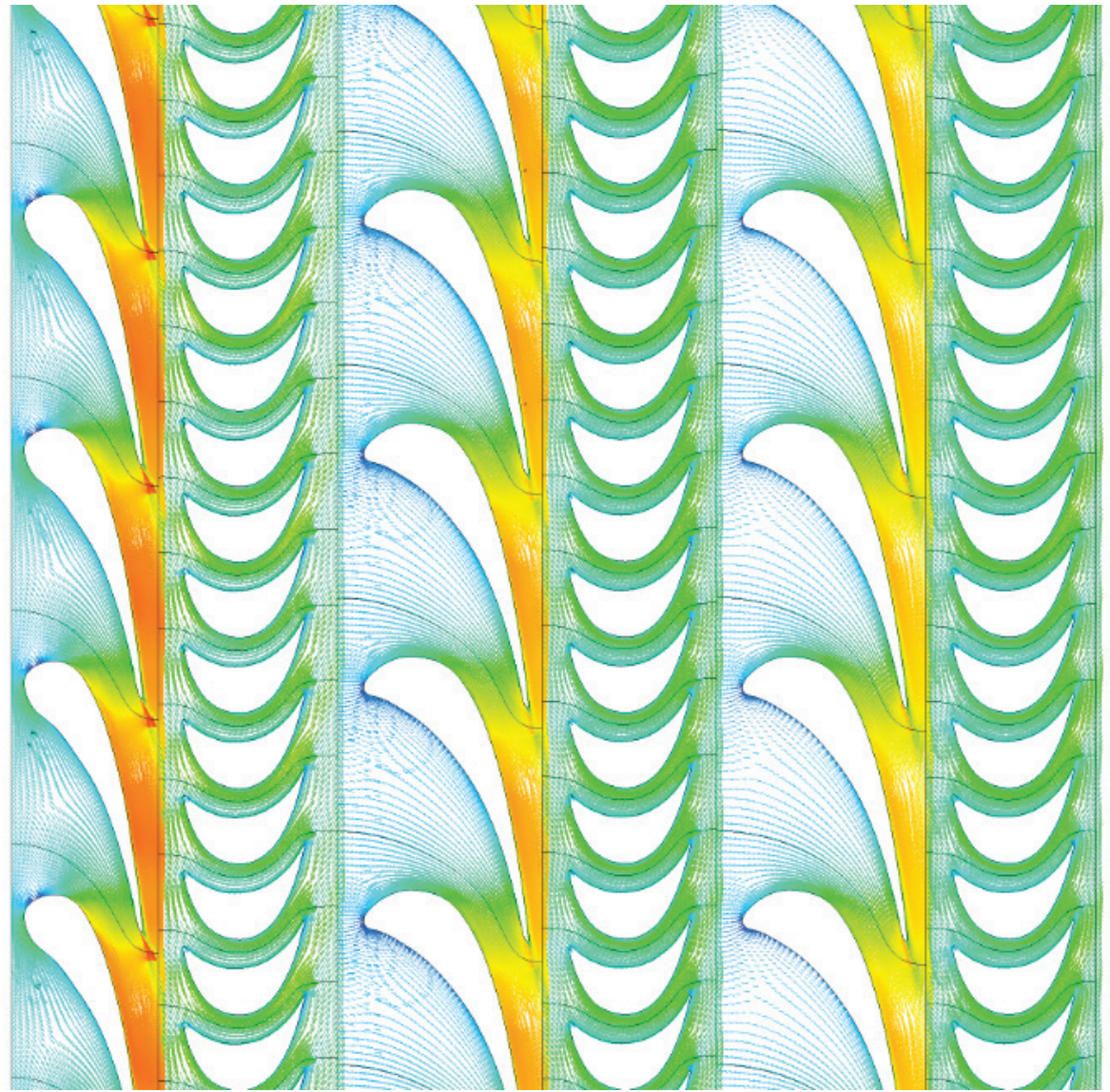

Fig. 12. Velocity field in 0.5 length stator blade, variant 8 


\section{Conclusions}

In this article, inlets and 1st stator blades of various geometries were analysed to obtain maximal turbine efficiency. Changing the inlet spiral from one pipe to two pipes increased the turbine efficiency from $87.3 \%$ to $88.87 \%$.

Changing the 1st stator geometry from S-5515A to S-9012A increased turbine efficiency.

The profile S-9012A increased the mass flow, so the length of the blade was decreased. Correction of the rotor blades was also necessary.

The calculation of steady flow including the outlet decreased the turbine efficiency from $88.87 \%$ to $85.87 \%$.

\section{Acknowledgement}

The authors wish to acknowledge NCBiR for the financial support of this work (POIR.04.01.04-00-0116/17).

\section{References}

[1] Kryłłowicz, W., Liskiewicz, G., Szwaja, S., Small Steam Turbines for Distributed Power Generation-Technical and Economic Condition, Energetyka, pp. 719-722, 2015.

[2] Dejcz, M. E., Filipov, G. A., Profile Collections of Axial Turbine Cascades, Maszinostrojenie, Moskov 1965. 